\title{
El 711 en la historiografía moderna y contemporánea (s. XVI-XIX)
}

\author{
Martín Ríos SALOMA \\ Instituto de Investigaciones Históricas \\ Universidad Nacional Autónoma de México \\ riosmartin76@gmail.com
}

\section{INTRODUCCIÓN}

La invasión islámica de la Península Ibérica ocurrida el año 711 es uno de los hechos históricos que mayor cantidad de tinta ha hecho correr, ya desde la propia época altomedieval. Los diversos autores que a lo largo de los siglos han abordado el problema se han interrogado sobre las causas que posibilitaron la invasión, sobre la cronología de los acontecimientos, sobre los cambios, las rupturas, las continuidades y las innovaciones operadas a partir del siglo VIII, sobre los sentidos profundos que tuvo dicho acontecimiento tanto en una perspectiva mediterránea como en el ámbito peninsular y, por último, sobre la manera en que dicho acontecimiento transformó -o no- la esencia hispana ${ }^{1}$. Pero hay un aspecto que solo ha comenzado a estudiarse recientemente, a saber, la forma en que la historiografía ha preservado, recreado y configurado una visión particular sobre dichos acontecimientos, tal y como muestran los títulos de las ponencias presentadas por Carlos de Ayala y Eduardo Manzano al congreso celebrado en Córdoba bajo el título "De árabes a moriscos" y que llevaban por título respectivamente "La memoria del 711 en la historiografía cristiana medieval y actual" y "La memoria del 711 en la historiografía sobre al-Andalus" .

Esta atención a la construcción historiográfica no es gratuita y obedece en realidad a la difusión, aunque tardía, de los postulados del giro lingüístico y del giro cultural, los cuales han subrayado el hecho de que todo discurso histórico no es sino en realidad producto de un proceso de selección que tiene unos objetivos y unas intencionalidades específicas y que se enmarca en un contexto histórico, historiográfico y cultural específico, de tal forma que los historiadores han cobrado plena conciencia sobre la

1 Frente a las tesis de Sánchez-Albornoz pueden resaltarse, por ejemplo, los trabajos de P. GUICHARD, $\mathrm{Al}$ Andalus. Estructura antropológica de una sociedad islámica en Occidente, Barcelona, 1976; P. CHALMETA, Invasión e islamización, Madrid, 1993; E, MANZANO, Conquistadores, emires y califas. Los omeyas y la formación de Al-Andalus, Madrid, 2006 o los congresos realizados de manera periódica bajo el título "Visigodos y Omeyas".

2 http://www.cchs.csic.es/es/node/277300 [para la información del congreso]. Evidentemente no me ha sido posible acceder al contenido de las mismas, de tal forma que habrá que esperar a su publicación para calibrar sus aportes que, sin duda, serán muy positivos. 
necesidad de estudiar el texto en relación con su contexto ${ }^{3}$. De esta suerte, el historiador no busca ya únicamente datos que puedan contrastarse con la documentación archivística, sino que, antes bien, se interroga por el o los sentidos de las construcciones retóricas contenidas en las crónicas y la forma en que el discurso historiográfico refleja una visión del pasado y contribuye a legitimar personas, grupos, instituciones o proyectos políticos ${ }^{4}$.

Es en este marco teórico apenas esbozado en el que se inserta la propuesta de análisis que someto a la consideración de mis colegas y que nace de una pregunta sencilla pero que encierra una gran complejidad: ¿cómo fue interpretada la invasión islámica del 711 por la historiografía de época moderna y contemporánea? La pregunta no es banal, puesto que nos lleva a interrogarnos, en realidad, sobre la forma en que la Monarquía Católica, primero, y España, después, construyeron su propia identidad y legitimaron diversos proyectos históricos y políticos, tales como la expansión atlántica, la conquista de Marruecos o, ya en el siglo XIX, la forma que el Estado debía adquirir tras el final del régimen fernandino. La lectura que planteo no pretende sino ofrecer perspectivas de análisis distintas que complementen y dialoguen con aquellas emanadas de los ámbitos histórico, arqueológico y filológico desarrolladas a lo largo de estos días.

Ante la falta de espacio, dividiré mi exposición en tres partes correspondientes a los siglos XVI y XVII, al siglo XVIII y al siglo XIX y me veré obligado a citar únicamente a los autores más representativos de cada corriente interpretativa.

\section{LOS SIGLOS XVI Y XVII}

A lo largo de la época moderna y hasta el último tercio de siglo XVII prevaleció la visión sobre la invasión musulmana asentada en las crónicas asturianas y desarrollada por Jiménez de Rada en el siglo XIII ${ }^{5}$. De esta suerte, la invasión fue presentada como un justo castigo de Dios por los pecados cometidos por los últimos reyes visigodos. Ello explica que, en realidad, la invasión quedara relegada a un segundo plano dentro del marco explicativo, puesto que lo que interesó resaltar a los autores -la mayoría de ellos pertenecientes al estamento eclesiástico-era, precisamente, el inicio de la Restauración realizada por Pelayo ${ }^{6}$. Así, el protagonismo no recaería en realidad

3 Para el desarrollo de estos postulados véanse: M. RÍOS SALOMA, "De la historia de las mentalidades a la historia cultural”, Estudios de historia moderna y contemporánea, 37 (2009), pp. 97-137 y J. AURELL, "Los efectos del giro lingüístico en la historiografía reciente", Rilce, 20 (2004), pp. 3-20.

4 En el ámbito del medievalismo español véanse, por ejemplo, los trabajos de J. AURELL, "From Genealogies to Chronicles. The Power of the Form in Medieval Catalan Historiography", Viator, 36 (2005), pp. 235-264 y de A DACOSTA, “¡Pelayo vive! Un arquetipo político en el horizonte ideológico del reino leonés", Espacio, Tiempo y Forma, Serie III. Historia Medieval, (10) 1997, pp. 89-135; Idem, "Relato y discurso en los orígenes del reino Asturleonés", Studia Historica. Historia Medieval, 22 (2004), pp. 153-168.

5 J. MORALEJO, J. GIL y J. I. RUIZ DE LA PEÑA (eds.), Crónicas asturianas, Oviedo, $1985 ;$ R. JIMÉNEZ DE RADA, Historia de los hechos de los españoles, Madrid, 1989.

6 Así lo diría Morales: "Él [Dios] quiso por rigurosa ejecución de su divina justicia, y por otros altos secretos de su providencia, pasar así a esta insigne providencia por el fuego de tan cruel tribulación, para que purgándola con el de la escoria de sus vicios, saliese de nuevo como de buena fragua, otra España limpia 
en los dirigentes musulmanes, sino en Witiza, Rodrigo y el conde don Julián, quienes encarnaban los vicios más detestables: lujuria, avaricia, traición. En este sentido, la violación de la Cava -o Florinda- no era sino el catalizador que llevaría a Julián a llamar a los musulmanes, personajes secundarios de la historia que únicamente cumplen con el papel asignado como ejecutores del castigo divino, de tal manera que su victoria en Guadalete no fue producto de su destreza o superioridad militar, sino que se logró en realidad por la inactividad, el afeminamiento y la molicie en la que vivían los godos, así como por la defección del partido witizano, de manera que, a decir de Ambrosio de Morales, "los Godos por Godos habían de ser vencidos, sin que otra nación sola pudiese prevalecer contra ellos"?

En la mayoría de los autores de los siglos XVI y XVII se aprecia un desconocimiento del mundo árabo-islámico y la ausencia de una visión "mediterránea" para explicar la conquista de la Península, de tal manera que se limitan a asentar que los musulmanes se hallaban sobre el norte de África y que "ambicionaban" la feraz y rica España, en una clara reminiscencia del laudus isidoriano. Por otra parte, a los musulmanes se les caracteriza con una serie de notas negativas que repiten los tópicos acuñados desde la Edad Media y los cronistas se refieren a ellos con términos como "infieles", "bárbaros" "canallas", "pérfidos", "execrables", etc. Particularmente interesante resulta el hecho de que ya en el siglo XVII autores como Diego Saavedra hablen de una "inundación sarracena" para referirse a la invasión, en una clara alusión a los pasajes bíblicos del diluvio que tenía como objetivo no solo señalar el hecho de que la invasión destruyó al reino visigodo -los autores reproducirían hasta la saciedad el célebre llanto por España- sino insistir en el hecho que Pelayo y los suyos serían elegidos por Dios para iniciar la restauración de España: la inundación no era una metáfora literaria, sino que era, en realidad, una auténtica metáfora política destinada a los súbditos de la monarquía católica dispersos por el orbe ${ }^{8}$.

Finalmente, la mayoría de los autores coinciden en señalar que el dominio islámico dejó a España en situación de servidumbre, aunque se reconoció el hecho de que los musulmanes permitieron vivir a muchos cristianos en calidad de "mixti-árabes". Asimismo, la mayoría de los autores refieren el matrimonio de Egilona -viuda de Rodrigo- con Abd-al-Asis, pero no lo interpretan como la concreción de unos pactos, sino como el último episodio de humillación de los cristianos.

y resplandeciente; toda Religiosa, toda Santa y puesta toda en alto celo de cristiandad y verdadera virtud, cual por muchos de los siglos siguientes sabemos que perseveró, siendo como es cosa de suma grandeza y soberana maravilla en la omnipotencia de Dios, sacar grandes bienes de algunos males" A. de MORALES, Corónica general de España que continuaba Ambrosio de Morales, coronista del rey nuestro señor don Felipe II, Madrid, 1761 [1574], vol. VI, pp. 417-418.

7 Ibidem, vol. VI, p. 378.

8 “"...] No vio el mundo caso más semejante al diluvio universal que este, porque como entonces rotas las cataratas del cielo se retiraban los hombres a salvarse de la creciente de las aguas en los montes, así huían a ellos los Españoles por librarse de aquella inundación de gente que había derramado África sobre las provincias de España”. D. SAAVEDRA FAJARDO, Corona gótica, castellana y austriaca, Madrid, 16581677, vol. I, p. 530. 


\section{EL SIGLO XVIII}

A lo largo del siglo XVII circularon diversas informaciones sobre el momento preciso en el que tuvieron lugar el desembarco de Tariq y la batalla de Guadalete, a la cual unos autores situaban en el verano y otros en noviembre. Con el objetivo de zanjar definitivamente la cuestión, en 1687 el marqués de Mondéjar dio a la luz un Examen chronológico del año en que entraron los moros en España ${ }^{9}$. La obra en cuestión refleja la introducción de los principios de la crítica histórica en España así como el surgimiento de un espíritu crítico que permitía, por vez primera, cuestionar el relato tradicional sobre la invasión, sustentándose dicha crítica en el criterio incontrovertible de la cronología, es decir, de la ciencia matemática, y por ello podemos considerar a Mondéjar como un precursor del pensamiento ilustrado.

Lo que nos interesa resaltar es el hecho de que por vez primera se tomó en cuenta la perspectiva islámica para explicar -o al menos para situar en el tiempo-la invasión, puesto que Mondéjar realizó un cotejo de las cuentas de la Era, la Natividad, el reinado de Heraclio y de la Hégira, así como de algunos pasajes de la llamada Crónica del moro Rasis para establecer la cronología.

Mondéjar concluyó que no había existido una sola invasión, sino que en realidad habían ocurrido tres incursiones islámicas. La primera tuvo lugar en el 709 "mucho antes de lo que escriben los nuestros, sino que efectivamente lo intentaron, emprendieron y dieron feliz principio a su conquista en el reinado de Witiza y antes de que llegara a la corona Rodrigo" ${ }^{0}$; esta primera incursión sería la que habría llevado a Tariq a conquistar el monte Calpe. La segunda incursión, a decir del marqués, tuvo lugar en el 710 y estuvo capitaneada por el general Abuzarat, quien debía ponerse bajo el mando de Tariq y sería en el marco de esta campaña que tendría lugar la batalla de Guadalete, ya en el 711. La última entrada se verificaría este mismo año y estaría comandada por Muza.

Amén de estas precisiones cronológicas a Mondéjar le corresponde otro mérito incontrovertible: el haber desestimado las leyendas en torno a la violación de la Cava y a la apertura del castillo encantado de Toledo como factores determinantes de la invasión y desplazar la atención hacia los factores políticos, a saber, la división y la lucha civil generada en el reino godo a la muerte de Witiza:

“[...] pusieron los ojos en Don Rodrigo, como varón legítimo del mismo del mismo tronco real en que se había conservado tantos años, aunque electiva, la Corona de los Godos, y aprobando el senado, compuesto de los prelados y principales señores del reino este dictamen, aclamaron por Rey a Rodrigo, con gran sentimiento y demostraciones exteriores de los más inmediatos parientes del difunto, y así se salieron luego de la corte con ánimo y determinada resolución de pasarse al ejército de los infieles, como lo ejecutaron, para facilitar con su número y con su mal ejemplo la total ruina de su patria, porque cuando ha de suceder la desgracia, los más interesados en ella suelen ser los primeros que concurren a solicitarla" $"$.

9 G. IBAÑEZ, MARQUÉS DE MONDÉJAR, Examen chronológico del año en que entraron los moros en España, Madrid, 1687.

10 Ibídem, p. 133.

11 Ibidem, p. 155. 
Lo que interesa resaltar en este caso es la forma en que los principios ilustrados permitieron que los autores abandonaran lentamente la explicación providencialista del acontecimiento y que se inclinaran por una explicación política e histórica de los mismos como ocurriría con el jesuita Francisco Masdeu ${ }^{12}$ y con el valenciano Gregorio Mayans y Síscar, quien en 1772 publicaría su famosa Vindicación del rey Vitiza ${ }^{13}$. Dicha explicación se realizaría bajo nuevos marcos políticos y culturales en los cuales los conceptos de patria y nación se habían resignificado y habían dado nacimiento a lo que Álvarez Junco ha llamado "patriotismo étnico"14. El resultado de todo ello sería que, al finalizar el siglo XVIII, los musulmanes no serían considerados más -o no solo- como enemigos religiosos que habían cruzado el Estrecho para colmar sus ambiciones, sino como enemigos extranjeros que buscaban apropiarse de la patria de los españoles.

Sin embargo y como parte también del pensamiento ilustrado, la civilización árabe comenzaría a ser conocida en sus fuentes y valorizada por sus aportes culturales, al punto que Masdeu podría referirse a los musulmanes como "nuestros árabes" y subrayar la forma en que esa cultura se había esparcido "por toda Europa"15.

\section{EL SIGLO XIX}

En el siglo XIX tanto el desarrollo de la ciencia histórica en general como del arabismo en particular permitieron lanzar nuevas miradas sobre la invasión musulmana ${ }^{16}$, las cuales se insertaron dentro de un marco también nuevo: la construcción de la identidad nacional española contemporánea ${ }^{17}$. Ello es importante porque como se ha señalado en varias ocasiones, lo que estaba en juego no eran solo datos y hechos positivos -nombres, fechas, lugares (recuérdese la polémica desatada en torno a la propuesta lanzada por los hermanos Olivier a propósito de la batalla de la Janda) ${ }^{18}$ sino el hecho de aceptar como propia, o no, la cultura árabe ${ }^{19}$. Al final se impuso una visión de la historia según la cual lo que distinguía a España de otras naciones europeas era precisamente el combate que a lo largo de ocho siglos los españoles habían mantenido contra los árabes y gracias al cual se había formado el carácter español que se había manifestado contra los ejércitos napoleónicos a principios de la centuria.

12 J. F. MASDEU, Historia crítica de España y de la cultura española, Madrid, 1783.

13 G. MAYANS Y SÍSCAR, Defensa del rey Vitiza, Valencia, 1722.

14 J. ÁlVAREZ JUNCO, Máter Dolorosa. La idea de España en el siglo XIX, Madrid, 2004, p. 61.

15 J. F. MASDEU, op. cit., 1783, vol. XII "España árabe", p. 1. Nótese cómo se concede una identidad propia a la civilización hispano-musulmana.

16 A. RIVIÈRE GÓMEZ, Orientalismo y nacionalismo español: estudios árabes y hebreos en la Universidad de Madrid (1843-1869), Madrid, 2000.

17 Véase ÁLVAREZ JUNCO, op. cit., 2004.

18 J. OLIVER Y HURTADO y M. OLIVER Y HURTADO, La batalla de Vejer o del lago de la Janda, comúnmente llamada de Guadalete, Granada, 1869.

19 S. FANJÚL, Al-Andalus contra España. La forja del mito, Madrid, 2000, p. 323; E. MANZANO MORENO, "La construcción del pasado histórico nacional", J. SISINIO PÉREZ GARZÓN (coord.), La gestación de la memoria. La historia de España al servicio del poder, Barcelona, 2002, pp. 33-62. 
Los debates desarrollados a lo largo de todo el siglo -hacia 1880 aún había quien hablaba de los pecados de los godos como causa de la invasión ${ }^{20}$ - culminarían en los trabajos de Aureliano Fernández Guerra, autor que acabaría desestimando de forma definitiva y con una crítica rigurosa las leyendas en torno a la Cava y valorándolas como parte del folklore popular ${ }^{21}$, y de Eduardo Saavedra, quien en 1892 publicó una Invasión de los árabes en España y cuyos asertos principales serían incorporados a la Historia de España dirigida por Cánovas del Castillo ${ }^{22}$. Para este académico de la historia la invasión -a la que denomina "la gran catástrofe nacional del siglo VIII" ${ }^{23}$ - se explicaba tanto por el impulso que poseían los árabes que se había adueñado en muy poco tiempo de todo el norte de África -lo que nos muestra su óptica mediterránea- como por las propias divisiones internas - una auténtica guerra civil- de los visigodos, de tal manera que los musulmanes serían los terceros en un conflicto interno que sabrían sacar partido, precisamente, de esa división. Una vez perdido Rodrigo, no habría autoridad política que pudiera resistir el empuje islámico y utilizando las viejas calzadas romanas y una "política de atracción" -representada por el matrimonio de Abdal Asis con Egilo$\mathrm{na}^{24}$ - fue posible dominar la mayor parte de la Península en muy poco tiempo.

\section{CONCLUSIONES}

En este rápido repaso a la forma en que la historiografía de época moderna y contemporánea se acercó a la invasión musulmana puede constatarse el hecho de que mientras la identidad española se construyó en términos religiosos, los autores mantuvieron vigente el modelo providencialista acuñado en la Edad Media, de tal suerte que los musulmanes fueron considerados únicamente como el instrumento de Dios para castigar a los cristianos por sus pecados. Cuando la identidad española comenzó a construirse a partir de elementos políticos, los autores se inclinaron por una explicación política de los sucesos, subrayando las divisiones internas de los visigodos que se conjugaban con el propio empuje islámico y su deseo de apropiarse de la fértil y rica España.

Para finalizar, es necesario insistir en el hecho de que el estudio de la historiografía debe hacer conscientes a los historiadores de que en buena medida nuestras interpretaciones y concepciones sobre la Edad Media son una herencia del siglo XIX, centuria en la cual el discurso historiográfico tenía la misión de contribuir a la forja de la Nación. De esta suerte, debemos estar alerta para, sin dejar de ponderar los aciertos y aportes más significativos de aquellos trabajos, no repetir ni asumir los prejuicios de aquellos que nos precedieron en la tarea de dilucidar el pasado.

20 M. MERRY Y COLON, Historia de España redactada por Manuel Merry y Colón, de la Real Academia de la Historia en el número correspondiente y catedrático propietario de esta asignatura en la universidad literaria de Sevilla, Sevilla, 1876, vol. II, pp. 76, 83-84.

21 A. FERNÁNDEZ GUERRA Y ORBE, Don Rodrigo y la Cava, Madrid, 1877; Idem, Caida y ruina del imperio visigótico español. Primer drama que se representó en nuestro teatro, Madrid, 1883.

22 E. SAAVEDRA FAJARDO, Invasión de los árabes en España, Madrid, 1892.

23 Ibidem, p. 1.

24 Ibidem, p. 136. 